\title{
Range expansion? First record of parti-coloured bat (Vespertilio murinus Linnaeus, 1758) in Tuscany, Italy
}

\author{
Gianna Dondini $^{1} \&$ Simone Vergari ${ }^{1}$ \\ ${ }^{1}$ Centro Naturalistico e Archeologico dell'Appennino Pistoiese via L. Orlando 100, I-51028 Campo Tizzoro, Pistoia (Italy). \\ *Corresponding author e-mail: svergar@tin.it
}

DOI: http://dx.doi.org/10.14709/BarbJ.8.1.2015.02 (C) 2015 Published by SECEMU.

Spanish title: Ampliación de rango distribuconal? Primera cita de murciélago bicolor (Vespertilio murinus, 1758) in Tuscany, Italy

\begin{abstract}
Vespertilio murinus is a paleartic species. In Italy it is a rare species, apparently confined in the northern regions. During a survey on Tuscany bats, the authors have found an individual in the town of Prato. This finding significantly expands the Italian range of this species southward. A greater sampling effort and new records will be essential for determining the status of the parti-coloured male specimens in Italy.
\end{abstract}

Key words: Vespertilio murinus, distribution, Italy

Parti-coloured bat (Vespertilio murinus L., 1758) is reported on a large portion of the Palearctic region. In northern Italy, Switzerland and France, the species reaches the western limit of its range (Mattei-Roesli et al. 2011, Lanza 2012). Its distribution within the area is heterogeneous, with a neat spatial segregation of males and females and a significant number of single migrating or wintering individuals (Dietz et al. 2009, Mattei-Roesli et al. 2011).

The taxon is considered to be partially migratory, with a maximum documented displacement of $1787 \mathrm{~km}$ from Russia to France (Hutterer et al. 2005). In Italy, the species is only known for the northern regions (Lanza 2012). The finding of a dead specimen has recently been reported in Piedmont (Toffoli \& Culasso 2011), while for Lombardy the capture of a specimen in the city of Milan is reported by De Carli and Fornasari (in verbis, cited in Agnelli et al. 2006).

Lanza (2012) does not quote this latest data and deems that the presence of $V$. murinus in Lombardy has still to be confirmed. The species has also been documented for the central and eastern Alps, in the regions of Friuli Venezia Giulia and Trentino Alto Adige (Ruffo \& Stoch 2005, Lanza 2012).

In Tuscany, the species was reported at Accesa Lake (Grosseto province) on the basis of surveys with bat detector
Pettersson D200 (eterodina) and direct observation while in

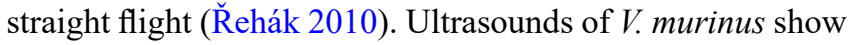
a great similarity with those of some other species present in Tuscany (eg. Nyctalus leisleri and Eptesicus serotinus), therefore this signal was not regarded as sufficient evidence of the presence of the species in the region, an area relatively far from its known distribution area.

As part of a monitoring program on bats in Tuscany, on $25^{\text {th }}$ September 2014 an individual was found on the wall of a terrace in the north-central part of the town of Prato (F.

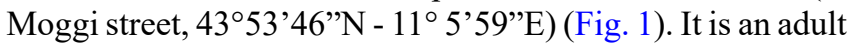
male identified as $V$. murinus on the basis of the diagnostic characters indicated by Dietz \& Von Helversen (2004). The specimen was in excellent physical condition, with a visible accumulation of fat between the shoulder blades. The following measures were taken: weight $19.9 \mathrm{~g}$; forearm $44.9 \mathrm{~mm}$; length of fifth finger (D5): $51.1 \mathrm{~mm}$; length of third finger (D3): $73.2 \mathrm{~mm}$. Dorsal pelage dark brown with white hair tips (Fig. 2); penis long and very narrow (Fig. 3). The individual has been photographed and its ultrasounds recordings were made when hand-released. Recordings were made with a Pettersson Elektronik D-240X ultrasound detector, connected to an Edirol R-09. The resulting sequence was then analyzed (BatSound 3.10) using a sampling frequency of $44.1 \mathrm{kHz}$ and a $512 \mathrm{pt}$ FFT. The spectrogram 


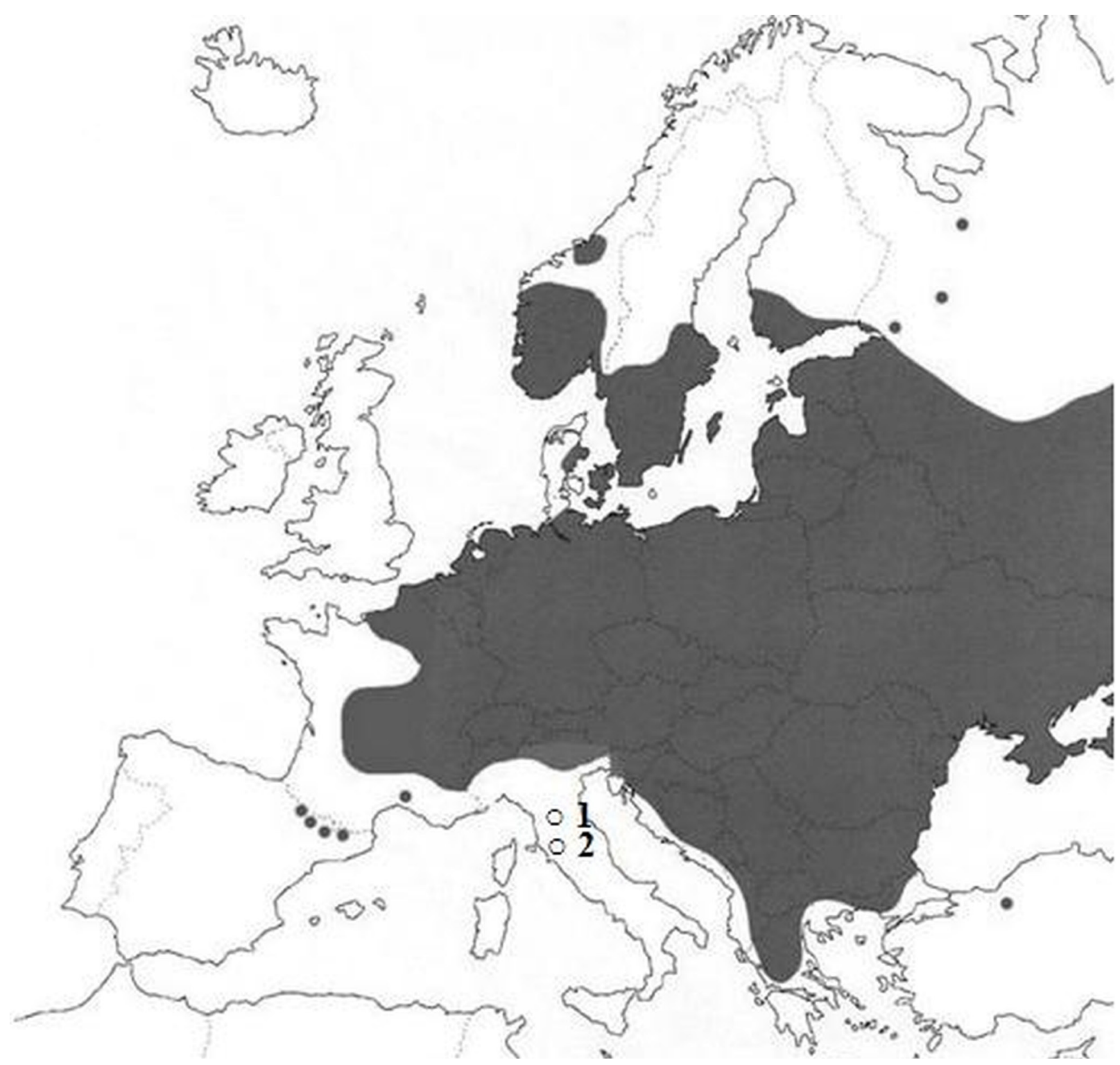

Fig. 1 - Record of Vespertilio murinus in Tuscany. 1= Prato; 2=Accesa Lake. Shaded area shows the distribution area of $V$. murinus according to Dietz et al. (2009).

analysis shows the following values: Start Frequency (SF): $50 \mathrm{KHz}$; End frequency (EF): $22 \mathrm{KHz}$; Frequency of peak Energy $($ Fmax $)=25.2 \mathrm{KHz}($ Obrist et al. 2004).

The discovery of this species in Tuscany enables us to expand its Italian range and European distribution significantly southwards. Males and females in this species have very different distribution ranges, with males reaching farther West and obviously South than females. This is likely a consequence of differences in their intra-species' niche differentiation between males and females (Safi et al. 2007, van Toor et al. 2011, Alberdi et al. 2012). Of course, the discovery of a single specimen does not allow to make assessments on the species' abundance and habitat use, which will be the subject of further study.

However it seems that the reporting of Parti-colored bat at the Accesa lake (Grosseto province) could well be validated, thus extending its presence farther south. Range expansion as a biogeographical phenomenon might be a possibility in
$V$. murinus, but again, this should be only exclaimed once reproduction has been confirmed outside the known range of reproduction; the evidence accumulates recently, that $V$. murinus does occur South of the alps, but so far, no one has reported on females, with or without reproduction.

Land use change is having an effect on many bat species. Climate change and urbanization may influence bat distribution and the case of $V$. murinus may well be driven by human-induced factors. For example In Italy, light pollution has even driven skull size variation in Pipistrellus kuhlii (Tomassini et al. 2014). A greater sampling effort and new records will be essential for determining the status of the parti-coloured male specimens in Italy. 


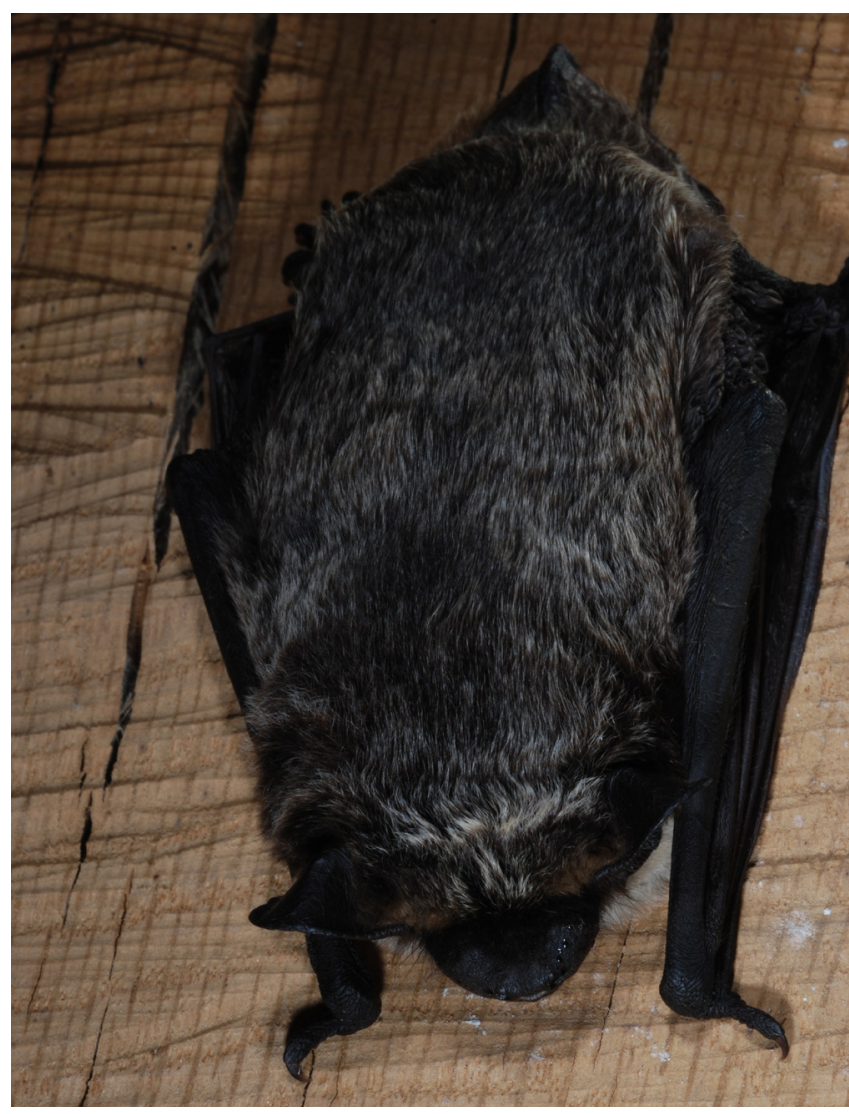

Fig. 2 - Male of Vespertilio murinus

\section{ACKNOWLEDGEMENTS}

Fieldwork was conducted under licence from the Italian Environment Ministry. We are grateful to Danilo Russo, Kamran Safi and an anonymous referee for providing constructive and insightful comments on this manuscript.

\section{REFERENCES}

Alberdi, A., Aihartza, J., Albero, J.C., Aizpurua, O., López-Baucells, A., Freixas, L., Puig-Montserrat, X., Flaquer, C. \& Garin, I. 2012. First records of the parti-coloured bat Vespertilio murinus (Chiroptera: Vespertilionidae) in the Pyrenees. Mammalia, 76:109111. Doi: http://dx.doi.org/10.1515/MAMM.2011.106

Dietz, C., Von Helversen, O. \& Nill, D. 2009. Bats of Britain, Europe and Northwest Africa. A\&C Black, $400 \mathrm{pp}$.

Dietz, C., Von Helversen, O. 2004. llustrated identification key to the bats of Europe. Elettronic Pubblication.

Agnelli, P., Martinoli, A., Pat riarca, E., Russo, D., Scaravelli, D. \& Genovesi, P. 2006. Guidelines for bat monitoring: methods for the study and conservation of bats in Italy. Quad. Cons. Natura, 19 bis, 1st Naz. Fauna Selvatica, Rome and Ozzano dell' Emilia (Bologna), 193 pp.

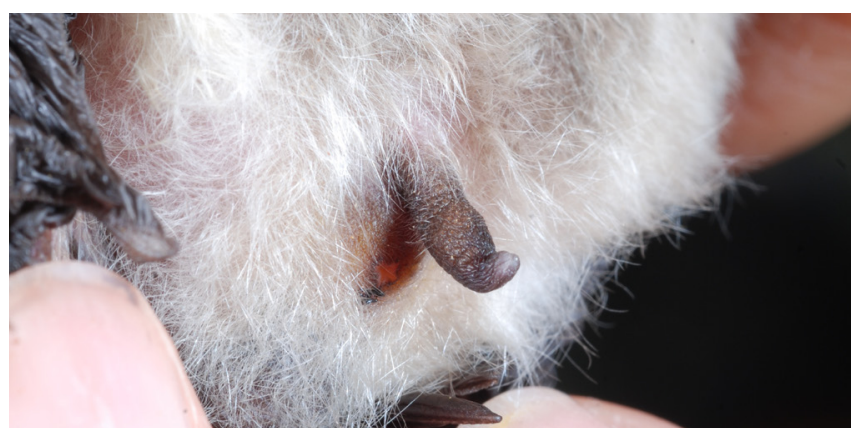

Fig. 3 - Penis of Vespertilio murinus

Hutterer, R., Ivanova, T., Meyer-Cords, C. \& Rodrigues, L. 2005. Bat migration in Europe. A review of banding data and literature. Federal Agency of Nature Conservation, Bonn, 162 pp.

Lanza, B. 2012. Chiroptera. Fauna d'Italia. Mammalia V. Chiroptera. Edizioni Calderini, Bologna; 786 pp.

Obrist, M.K., Fluckiger, P.F. \& BOesCh, R. 2004. Variability in echolocation call design of 26 Swiss bat species: consequences, limits and options for automated field identification with a synergetic pattern recognition approach. Mammalia 69: 307-322. Doi:_http://dx.doi. org/10.1515/mamm.2004.030

ŘEнÁk, Z. 2010. Some faunistic data on the bats of Italy. Vespertilio 13-14: 113-119.

Russo, D., Jones, G. 2002. Identification of twenty-two bat species (Mammalia: Chiroptera) from Italy by analysis of time-expanded recordings of echolocation calls. Journal of Zoology London 258: 91-103. Doi: http://dx.doi.org/10.1017/S0952836902001231

SAfi, K., König, B. \& Kerth, G. 2007. Sex differences in population genetics, home range size and habitat use of the parti-colored bat (Vespertilio murinus, Linnaeus 1758) in Switzerland and their consequences for conservation. Biological Conservation, 137: 28-36. Doi: http://dx.doi.org/10.1016/j.biocon.2007.01.011

Toffoli, R., Culasso, P. 2011. Vespertilio murinus (Linneo, 1758): una nuova specie per la chirotterofauna piemontese. Bollettino Museo regionale Scienze naturali Torino, 28: 191-196.

Tomassini, A., Colangelo, P., Agnelli, P., Jones, G. \& Russo, D. 2014. Cranial size has increased over 133 years in a common bat, Pipistrellus kuhlii: a response to changing climate or urbanization? Journal of Biogeography, 41: 944-953. Doi: http://dx.doi. org/10.1111/jbi.12248

VAN ToOR, M.L., JABERG, C., \& SAFI, K. 2011. Integrating sex-specific habitat use for conservation using habitat suitability models. Animal Conservation, 14: 512-520. Doi: http://dx.doi.org/10.1111/j.14691795.2011.00454.x 